\title{
Two Year Experience with Tolvaptan in Patients with Rapidly Progressing Polycystic Kidney Disease
}

\author{
Covadonga López del Moral Cuesta*, Gema Fernández Fresnedo, Luis Martín Penagos, \\ Jaime Mazón Ruiz, Marina De Cos Gómez, José Luis Pérez Canga, Mara Serrano Soto, \\ Milagros Heras Vicario, Emilio Rodrigo Calabia, Juan Carlos Ruiz San Millán
}

Nephrology Department, Hospital Universitario Marqués de Valdecilla, Santander, Cantabria, Spain

Email address:

covalopezdelmoral@gmail.com (C. L. del M. Cuesta)

${ }^{*}$ Corresponding author

\section{To cite this article:}

Covadonga López del Moral Cuesta, Gema Fernández Fresnedo, Luis Martín Penagos, Jaime Mazón Ruiz, Marina De Cos Gómez, José Luis Pérez Canga, Mara Serrano Soto, Milagros Heras Vicario, Emilio Rodrigo Calabia, Juan Carlos Ruiz San Millán. Two Year Experience with Tolvaptan in Patients with Rapidly Progressing Polycystic Kidney Disease. American Journal of Clinical and Experimental Medicine. Vol. 8, No. 3, 2020, pp. 35-41. doi: 10.11648/j.ajcem.20200803.12

Received: November 19, 2019; Accepted: December 5, 2019; Published: June 9, 2020

\begin{abstract}
Background: Autosomal dominant polycystic kidney disease (ADPKD) is a genetic disorder in which patients progress to end stage chronic kidney disease. Tolvaptan, vasopressin V2 receptor antagonist, has been postulated as an effective treatment to slow this progression. METHOD: All patients with ADPKD in whom treatment with tolvaptan was initiated were selected, with follow-up until 30 June 2019 . The initial dose was $45 / 15 \mathrm{mg} /$ day, with monthly titration at $60 / 30$ $\mathrm{mg}$ and 90/30 mg. Monthly anthropometric, analytical and adverse effects were collected. RESULT: We present results from of 12 patients (mean age $39.8+/-7.3$ years; 4 men and 8 women). 100\% of the patients were selected to start tolvaptan because they had evidence of rapidly progressing disease, with a confirmed annual estimated filtration rate (eGFR) decline $\geq 5$ $\mathrm{mL} / \mathrm{min} / 1.73 \mathrm{~m} 2$ in 1 year, and/or $\geq 2.5 \mathrm{~mL} / \mathrm{min} / 1.73 \mathrm{~m} 2$ per year over a period of 5 years. All patients had symptoms derived from aquaresis from the beginning of treatment. A decline in eGFR was observed in all patients after starting tolvaptan, dropping $38,8 \%$ from its baseline in one patient. In two patients the drug was temporarily discontinued due to hepatotoxicity, with subsequent recovery. Conclusion: Symptoms derived from aquaresis are very common and it is not known if they can limit the tolerability of the drug. An initial decline of the eGFR is observed during the follow-up. Close monitoring of liver function is important because of the potential hepatotoxicity of tolvaptan. More follow-up time is needed to asses the long-term efficacy and safety of tolvaptan.
\end{abstract}

Keywords: Autosomal Dominant Polycystic Kidney Disease, Adpkd, Tolvaptan, Hepatotoxicity, Aquaresis

\section{Introduction}

Autosomal dominant polycystic kidney disease (ADPKD) is the most common monogenic kidney disease, with a prevalence estimated at approximately 1 in every 400-1000 inhabitants [1-2]. It is a disease with a significant social impact and is the fourth most frequent cause of chronic endstage renal disease (ESRD). ADPKD is associated with other clinical manifestations, such as arterial hypertension (AHT), polycystic liver disease, valvular abnormalities, and intracranial aneurysms [3-4]. In recent years, understanding of the pathophysiology of the disease has advanced [5]. In the 1990s, the genes responsible for ADPKD, PKD1 and PKD2, were identified [6-9]. Up to $78 \%$ of patients have a mutation on chromosome 16 (PKD1 locus), and in $14 \%$ the mutation is on chromosome 4 (PKD2 locus). The PKD2 mutation produces a less severe phenotype. It is estimated that no mutation is detected in approximately $8 \%$ of patients, while the GANAB7 gene [10], which produces a milder disease phenotype, is identified in a smaller percentage of patients. The proteins encoded by these genes alter intracellular calcium homeostasis, leading eventually to cell proliferation and generation of cysts [11-12]. The disease is diagnosed primarily by ultrasound, and a genetic study is unnecessary if the diagnostic imaging and clinical 
picture are clear [13-16]. The treatment of ADPKD is based on the control of cardiovascular risk factors, mainly AHT [17]. Since we know that activation of vasopressin V2 receptors promotes the generation of cyclic adenosine monophosphate (cAMP) (and, therefore, cystogenesis), tolvaptan, a vasopressin V2 receptor antagonist, has been proposed as a promising treatment in in adult patients with chronic kidney disease stages 1-4 with evidence of rapidly progressing disease [18]. The effectiveness of this drug in delaying disease progression was demonstrated in the TEMPO 3:4 and TEMPO 4:4 studies [19-21]. Tolvaptan was approved in Spain in 2017 and is indicated in patients defined as rapid progressors. These are patients with a confirmed annual glomerular filtration rate (GFR) reduction greater than or equal to $5 \mathrm{ml} / \mathrm{min} / 1.73 \mathrm{~m} 2$ in a year and/or greater than or equal to $2.5 \mathrm{ml} / \mathrm{min} / 1.73 \mathrm{~m} 2$ per year for a period of 5 years, or an increase in total kidney volume (TKV) of more than $5 \%$ per year, as measured by renal MRI [22-23]. Other criteria of rapid progression to take into account are kidney length $>16.5 \mathrm{~cm}$ measured by ultrasound in patients younger than 45 years, a truncating PKD1 mutation, and early onset of clinical symptoms, according to a PRO-PKD predictive model score $>6$ [24]. Patients who do not meet criteria for rapid progression at the time of the assessment should be reassessed in 3-5 years if they have family members who have needed renal replacement therapy (RRT) before the age of 58 years. As tolvaptan was approved recently in Spain, clinical experience is still limited. The aim of this study was to investigate the clinical experience of tolvaptan treatment in rapid progressors.

\section{Materials and Methods}

All patients with polycystic kidney disease who started treatment with tolvaptan in the autonomous community of Cantabria were selected. According to the recommendations for use of tolvaptan in ADPKD, patients younger than 18 years and older than 50 years were excluded [18]. Moreover, patients with chronic kidney disease stage 5 were not candidates to start treatment with tolvaptan. All patients selected to initiate tolvaptan treatment presented signs of rapid progression, with a decline in GFR greater than or equal to $5 \mathrm{ml} / \mathrm{min} / 1.73 \mathrm{~m} 2$ in 1 year or an annual fall in GFR greater than or equal to $2.5 \mathrm{ml} / \mathrm{min} / 1.73 \mathrm{~m} 2$ during 5 years. No patients were selected to start tolvaptan due to an annual increase in TKV as measured by MRI, as retrospective renal MRIs were not available, nor for any other criterion of rapid progression. All study candidates were evaluated before starting treatment, and the criteria for contraindication of the drug were reviewed: increase of transaminases more than 8 times the normal value, hypersensitivity, hypovolemia, hypernatremia, inability to perceive thirst, pregnancy or breast-feeding. Scenarios in which the drug can be administered with caution were also reviewed, including: cirrhosis, dehydration, urinary obstruction in the case of male patients (benign prostatic hypertrophy), electrolyte imbalance, diabetes mellitus, hyperuricemia, and use of other drugs that interact with tolvaptan (CYP3A inhibitors). All patients were monitored on a monthly basis, and after the 18th month of follow-up they were monitored every 3 months. Data were collected until 30 June 2019. The initial dose was $45 \mathrm{mg}+15 \mathrm{mg}$ per day, with monthly titration to 60 $\mathrm{mg}+30 \mathrm{mg}$ and $90 \mathrm{mg}+30 \mathrm{mg}$. Anthropometric, clinical laboratory, and blood pressure (BP) data were collected. The analytical data included, but were not limited to, liver function tests, serum sodium, and osmolarity in blood and urine. Any adverse side effects associated with tolvaptan were recorded. Means and standard deviation (SD) were calculated using IBM SPSS Statistics 22 software.

\section{Results}

We report the results of 12 patients (mean age $39.8+/-7.3$ years; 4 men and 8 women). Mean time of follow-up was 11.3 months (range 1-24). Demographic characteristics of the study patients are shown in Table 1 . The selected patients had no significant comorbidities, while AHT was diagnosed in all of them. One of the patients selected to start tolvaptan was diagnosed with diabetes mellitus type 2 . None of the patients was receiving CYP3A inhibitors, and none presented cirrhosis or any of the other situations described above in which caution should be exercised with the use of this drug. The first patient began treatment on June 2, 2017. Four patients discontinued tolvaptan, as they were unable to tolerate aquaretic-related symptoms. One of them discontinued treatment before completing the ninth month, another one discontinued before completing the fifth month, other patient discontinued treatment at the second month, and another one discontinued it before completing the first month of follow-up. All patients underwent monthly tolvaptan dose titration, and all reached the maximum dose of tolvaptan (120 $\mathrm{mg}$ split into two doses: $90 \mathrm{mg}+30 \mathrm{mg}$ ) by the second month of follow-up. The second daily dose of tolvaptan was administered 8 hours after the first dose in all patients, as indicated by the prescribing information of the drug. Mean baseline GFR (CKD-EPI) of patients before treatment was $64.3+/-17.7 \mathrm{ml} / \mathrm{min} / 1.73 \mathrm{~m} 2$. Mean clinical laboratory and anthropometric data are listed in Table 2. All patients presented a decline in GFR after starting tolvaptan. Renal function variables during follow-up are shown in Figure 1. The maximum reduction in GFR was $38.8 \%$ compared to baseline (decline of $21.0 \mathrm{ml} / \mathrm{min} / 1.73 \mathrm{~m} 2$ ), observed in 1 patient. The 10 remaining patients had a maximum decline in GFR from baseline of 17.0, 17.0, 12.0, 11.0, 9.5, 5.0, 4.2, 4.0, 0.0 and $0.0 \mathrm{ml} / \mathrm{min} / 1.73 \mathrm{~m} 2$ respectively. Patients who were followed up for longer periods showed a greater recovery of renal function after the initial decline.

Clinical laboratory monitoring revealed a reduction in urine osmolality during the months of follow-up. All patients presented aquaretic-related symptoms (thirst, polyuria, nocturia, polydipsia) after starting treatment. None of the patients reported an increase in symptoms after increasing the dose of the drug. One patient had clinical improvement after 
starting treatment with tolvaptan, with resolution of pain in the renal fossa caused by the presence of a large cyst. This same patient showed raised transaminases [aspartate aminotransferase (AST) and alanine aminotransferase (ALT)] at month 6 of treatment when receiving doses of tolvaptan of $90 \mathrm{mg}+30 \mathrm{mg}$, with values up to 8 times the limit of normal in the case of AST (ALT $179 \mathrm{U} / \mathrm{L}$ [2-40], AST $483 \mathrm{U} / \mathrm{L}$ [135]). The patient was asymptomatic at all times, with no jaundice, no right hypochondrial pain, and no other clinical symptoms. In view of the elevated transaminases, the drug was discontinued, and a clinical laboratory test performed 72 hours later showed normalization of AST and ALT values. Following the discontinuation of tolvaptan, the patient began to report the same symptoms that she presented before starting treatment, with pain in the left renal fossa. As her transaminase values had normalized and following the indications of the prescribing information for the drug, treatment was restarted, but at lower doses $(60 \mathrm{mg}+30 \mathrm{mg})$. Weekly clinical laboratory tests were performed, including monitoring of liver function tests; raised AST and ALT values were observed 1 week after restarting tolvaptan, but levels did not exceed 8 times the limit of normal. Since her transaminases began to rise again, the dose was reduced to 45 $\mathrm{mg}+15 \mathrm{mg}$; the patient was continuing to receive this dose at the time of submission of this paper. The course of this patient's liver function tests is shown in Figure 2. Another patient showed raised transaminases at month 11 of treatment with tolvaptan, receiving doses of $90 \mathrm{mg}+30 \mathrm{mg}$, with values up to less than 2 times the limit of normal (AST 37 $\mathrm{U} / \mathrm{L}$, ALT $56 \mathrm{U} / \mathrm{L}$ ). The patient was asymptomatic, and the drug was discontinued. A laboratory test was performed 72 hours later, and the values of AST and ALT had normalized. Then, tolvaptan was restarted at lower doses $(60 \mathrm{mg}+30$ $\mathrm{mg}$ ), and the patient has maintained this dose until the time of submission of this paper. Elevated AST and ALT were not observed again in this patient nor in any of the other patients receiving tolvaptan.

Table 1. Demographic data of the patients who started treatment with tolvaptan. Age (years): mean and standard deviation (SD). Gender: male (M) / female (F). Baseline GFR measured by CKD-EPI: mean and SD. Other variables are expressed in absolute number and percentage (\%).

\begin{tabular}{ll}
\hline $\mathbf{N}=\mathbf{1 2}$ & $39.8 \pm 7.3$ \\
\hline Age (years) & $4 / 8$ \\
Gender (M/F) & $64.3 \pm 17.7$ \\
Baseline GFR (ml/min/m2) & $12(100 \%)$ \\
AHT & $12(100 \%)$ \\
Treatment with ACE inhibitors/ ARAII & $6(50 \%)$ \\
Other antihypertensive drugs & $1(8.3 \%)$ \\
Diabetes mellitus type 2 & $4(33.3 \%)$ \\
Dyslipidemia & $10(83.3 \%)$ \\
Family history of ADPKD & $3(25.0 \%)$ \\
Intracranial aneurysm & $0(0.0 \%)$ \\
Valvular abnormalities & $10(83.3 \%)$ \\
Liver cysts & $2(16.6 \%)$ \\
Nephritic colic & $2(16.6 \%)$ \\
Kidney cyst infection & \\
\hline
\end{tabular}

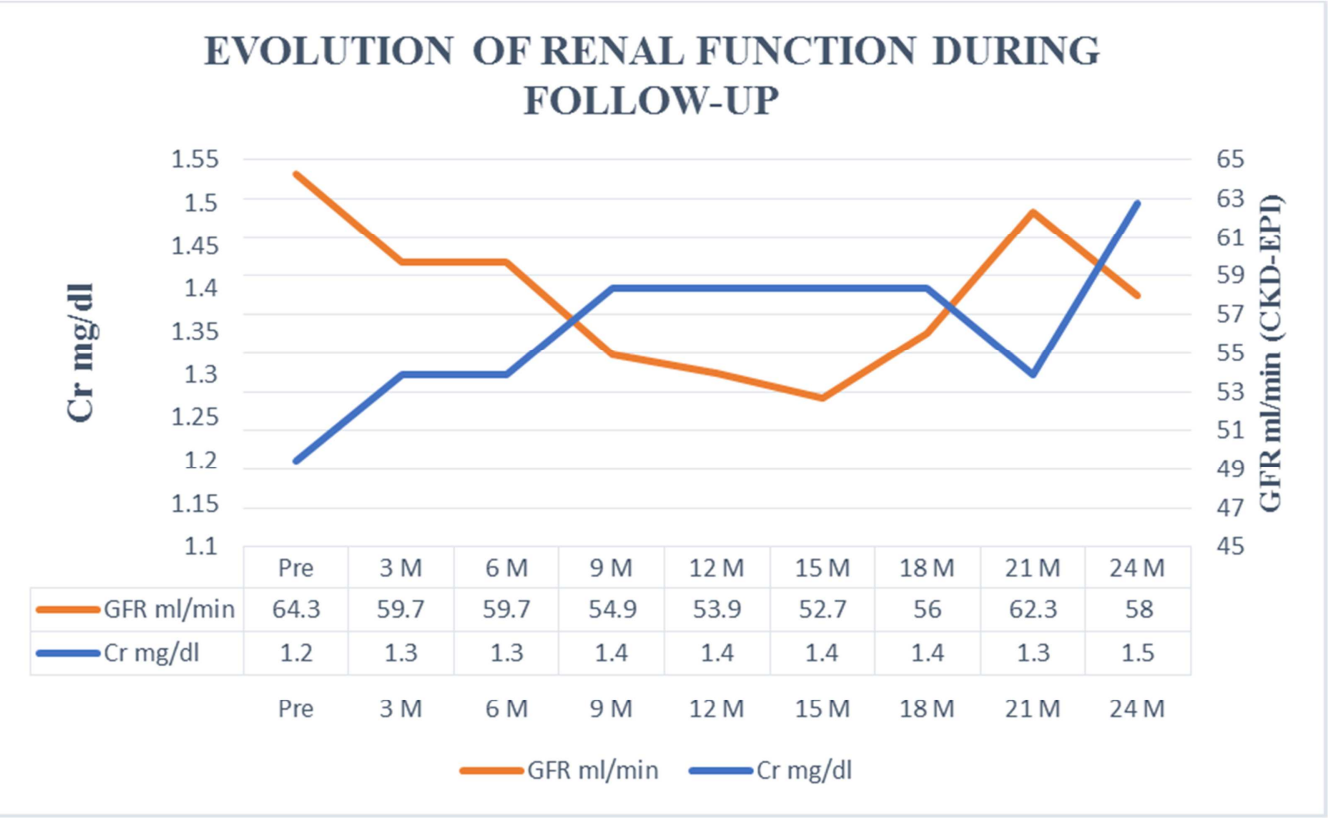

Figure 1. Evolution of renal function during follow-up. Mean plasma creatinine (Cr; mg/dl) and glomerular filtration rate (GFR measured by CKD-EPI; $\mathrm{ml} / \mathrm{min} / 1.73 \mathrm{~m} 2$ ) during quarterly follow-up. 
Table 2. Mean analytical and anthropometric values \pm standard deviation (SD) during the quarterly follow-up. Na=serum sodium. BOsm=blod osmolarity. $U O s m=$ urine osmolarity. $A S T=$ aspartate aminotransferase. $A L T=$ alanine aminotransferase. $S B P=$ systolic blood pressure. $D B P=$ diastolic blood pressure.

\begin{tabular}{lllll}
\hline MEAN VALUES & Pre-tolvapt An $(\mathbf{n}=\mathbf{1 2})$ & month 3 $(\mathbf{n}=\mathbf{1 0})$ & MONTH 6 $(\mathbf{n}=\mathbf{8})$ & MONTH 9 (N=6) \\
\hline $\mathrm{Na} \mathrm{mEq} / \mathrm{L}$ & $140.5 \pm 1.6$ & $141.2 \pm 1.9$ & $141.2 \pm 1.2$ & $141.1 \pm 1.8$ \\
BOsm mOsm/kg & $302.2 \pm 7.3$ & $301.5 \pm 5.5$ & $303.8 \pm 4.3$ & $303.0 \pm 4.3$ \\
UOsm mOsm/kg & $540.0 \pm 246.6$ & $179.8 \pm 62.0$ & $235.2 \pm 153.1$ & $255.5 \pm 93.6$ \\
AST U/L & $19.1 \pm 5.6$ & $19.5 \pm 5.7$ & $79.6 \pm 163.1$ & $21.0 \pm 5.0$ \\
ALT U/L & $17.3 \pm 7.3$ & $15.7 \pm 5.3$ & $40.5 \pm 56.5$ & $18.3 \pm 8.9$ \\
weight Kg & $85.2 \pm 23.1$ & $81.4 \pm 21.3$ & $80.6 \pm 21.8$ & $84.2 \pm 20.6$ \\
SBP mmHg & $130.5 \pm 21.3$ & $133.5 \pm 8.6$ & $126.8 \pm 11.7$ & $128.0 \pm 8.0$ \\
dbp mmhg & $83.6 \pm 19.2$ & $85.1 \pm 8.3$ & $82.7 \pm 9.8$ & $83.8 \pm 7.7$ \\
\hline
\end{tabular}

Table 2. Continued.

\begin{tabular}{llllll}
\hline MEAN VALUES & MONTH 12 $(\mathbf{N}=4)$ & MONTH 15 $(\mathbf{N}=4)$ & MONTH 18 $(\mathbf{N}=4)$ & MONTH 21 (N=3) & MONTH 24 (N=2) \\
\hline Na mEq/L & $140.2 \pm 1.7$ & $141.0 \pm 2.9$ & $142.5 \pm 0.5$ & $142.0 \pm 1.0$ & $144.5 \pm 0.7$ \\
BOsm mOsm/kg & $300.0 \pm 4.3$ & $299.0 \pm 3.6$ & $299.7 \pm 3.9$ & $303.3 \pm 4.0$ & $306.0 \pm 4.2$ \\
UOsm mOsm/kg & $234.0 \pm 58.1$ & $221.7 \pm 52.0$ & $238.7 \pm 36.5$ & $246.0 \pm 34.7$ & $199.0 \pm 8.4$ \\
AST U/L & $24.7 \pm 5.7$ & $20.2 \pm 4.5$ & $19.0 \pm 5.4$ & $18.6 \pm 3.0$ & $19.5 \pm 0.7$ \\
ALT U/L & $17.0 \pm 4.1$ & $15.0 \pm 2.4$ & $15.0 \pm 4.6$ & $14.0 \pm 2.0$ & $21.5 \pm 14.8$ \\
weight Kg & $72.1 \pm 8.3$ & $71.4 \pm 8.1$ & $72.8 \pm 9.1$ & $72.7 \pm 12.0$ & $80.2 \pm 6.0$ \\
SBP mmHg & $126.7 \pm 14.8$ & $125.5 \pm 13.2$ & $127.2 \pm 6.2$ & $129.3 \pm 16.8$ & $129.0 \pm 1.4$ \\
dbp mmhg & $74.7 \pm 11.1$ & $78.5 \pm 5.7$ & $72.2 \pm 8.4$ & $77.0 \pm 11.1$ & $78.5 \pm 12.0$ \\
\hline
\end{tabular}

\section{COURSE OF LIVER FUNCTION IN A PATIENT WITH HEPATOTOXICITY SECONDARY TO TOLVAPTAN}

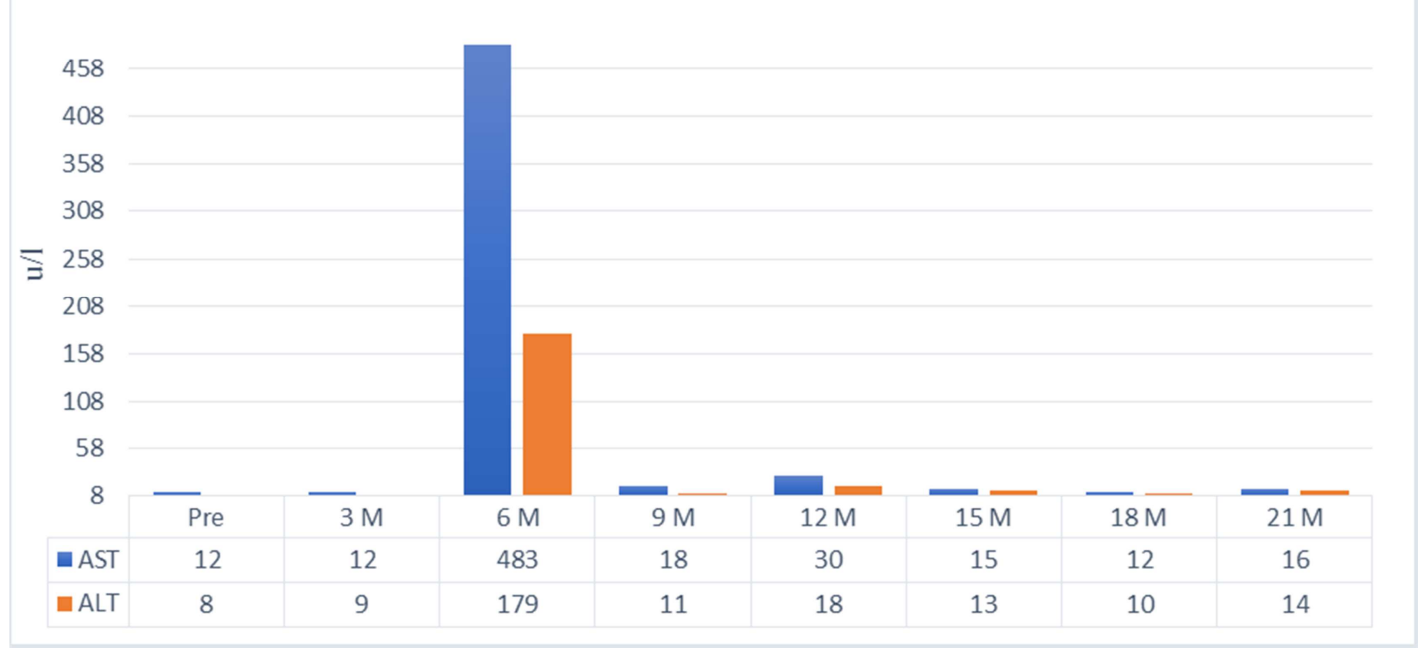

Figure 2. Course of liver function in a patient with hepatotoxicity secondary to tolvaptan [Aspartate aminotransferase (AST) and alanine aminotransferase (ALT)]. Normal laboratory values: AST: 1-35 U/L; ALT 2-40 U/L.

\section{Discussion}

ADPKD is the most common hereditary kidney disease, and patients progress to ESRD, with $10 \%$ receiving RRT (dialysis or kidney transplant) [2]. Disease management was previously based solely on the control of cardiovascular risk factors and the prevention and treatment of associated complications. In recent years, knowledge of the disease has advanced, and the genes involved (PKD1 and PKD2) in its pathophysiology have been identified [6]. The TEMPO 3:4 study [20] and subsequently the TEMPO 4:4 extension study [21] support the use of tolvaptan, a vasopressin V2 antagonist, as a treatment to delay disease progression and loss of renal function. The TEMPO 3:4 study included 1157 patients aged between 18 and 50 years in a 3-year follow-up; participants had GFR greater than or equal to $60 \mathrm{ml} / \mathrm{min}$ and TKV greater than or equal to $750 \mathrm{ml}$. The annual increase in TKV was lower in patients in the tolvaptan group than in the placebo group (an annual increase of $2.8 \%$ in TKV in patients who received tolvaptan, compared to an annual increase of $5.5 \%$ in patients who received placebo). The annual decline in renal function was slower in patients who received tolvaptan (decline of $-2.61 \mathrm{mg} / \mathrm{ml}$ creatinine per year, compared to an annual decline of $-3.81 \mathrm{mg} / \mathrm{ml}$ creatinine in patients receiving placebo). In this study, the rate of adverse events was similar in both groups, while patients receiving tolvaptan presented aquaretic-related 
symptoms [20]. Patients who had completed 3 years in the TEMPO 3:4 study continued to be followed up in the TEMPO 4:4 study. The efficacy and safety of treatment was evaluated for another 2 years: patients who had initially received tolvaptan continued with this treatment until they completed 5 years of treatment ("early treatment"), and patients who had received placebo were switched to receive tolvaptan for 2 years ("late treatment"). No statistically significant differences were observed in the change in TKV between the two patient groups. In contrast, differences were observed in the secondary variable of change in GFR, demonstrating the beneficial effect of tolvaptan on disease progression [21].

Polycystin mutations, encoded by the genes mentioned above, disturb intracellular calcium regulation and increase cAMP signaling. Activation of these V2 receptors increases cAMP and, consequently, cell proliferation and cyst generation. For this reason, inhibiting these receptors with the use of tolvaptan seems to slow down cystogenesis and the progression of ADPKD.

Patients who are candidates for this treatment are defined as rapid progressors [18]. There are different criteria for selecting patients who are at a higher risk of progression: in our setting, the criterion used to select patients was a decline in annual GFR. Given the unavailability of renal MRIs, we could not include patients with rapid progression according to the TKV criterion. In the future, now that more MRI test results are available, we will probably be able to include a greater number of patients with the criterion of progression corresponding to an annual increase in TKV measured by MRI [15-22-23].

All patients who started treatment in our setting were followed up on a monthly basis until month 18 , and after that patients were monitored every 3 months. They all showed a decline in GFR in the first few months, including 1 patient who had a $38.8 \%$ maximum decrease from baseline GFR. In the TEMPO 3:4 study, an initial decline in GFR was observed at 1 year of follow-up in patients treated with tolvaptan, similar to that seen at 1 year of follow-up in patients who received placebo. However, patients who received the drug showed a subsequent improvement in GFR. In this study, an annual decline of GFR of $2.72 \mathrm{ml} / \mathrm{min}$ was observed in patients receiving tolvaptan, compared to an annual decline of $3.70 \mathrm{ml} / \mathrm{min}$ in patients receiving placebo [20]. This beneficial effect on disease progression was confirmed in the TEMPO 4:4 study [21]. The patients who were followed up for the longest periods in our study showed a greater recovery of renal function. Four of our patients recovered their baseline GFR during their last month of follow-up. Despite this, more time would be needed to confirm the delay in the loss of renal function described in previous studies.

The administration of tolvaptan was associated with aquaretic-related symptoms in all patients, but no increase in the intensity of these symptoms was reported during dosing titration. Because of these symptoms, it is essential that the patient has access to water to ensure proper hydration.
Aquaretic-related symptoms can limit drug tolerability, and in our study led to treatment discontinuation in 4 patients. This is consistent with published studies, since in the TEMPO 3:4 study, a greater incidence of these symptoms was reported in patients treated with tolvaptan, with a treatment discontinuation rate of $8.3 \%$ due to associated clinical symptoms [20]. All patients in our series underwent clinical laboratory tests, including osmolarity in blood and urine: $100 \%$ of patients demonstrated a reduction in urine osmolality (UOsm). The decline in UOsm occurs in patients treated with tolvaptan, and previous studies have reported that a greater suppression of UOsm is associated with a greater benefit in renal function [25].

Hepatotoxicity is a potential side effect that appeared in two of our patients. One patient showed raised transaminases with values up to less than 2 times the limit of normal, and with temporary discontinuation of the drug the values of AST and ALT normalized. Another patient showed a more important rise in ALT and AST levels, above 8 times the limit of normal. In this patient, tolvaptan was discontinued according to the indications of the prescribing information, but it was later reintroduced when transaminases values normalized. In the TEMPO 3:4 study, tolvaptan was discontinued due to liver function changes in $1.2 \%$ of patients [20]. Due to this potential liver toxicity, it is of vital importance that complete monthly clinical laboratory monitoring, including liver function tests, are performed every month during the first 18 months of treatment.

\section{Conclusion}

Treatment with tolvaptan therefore seems to be a promising option that can slow the progression of ADPKD. Patients will have to be followed up for a longer period to assess the true efficacy of the drug in delaying loss of renal function, and perhaps then we can consider the inclusion of patients over the age of 50 years with rapid disease progression, in whom the benefit of the administration of the drug is clear. The longer follow-up of patients treated with tolvaptan may also provide more data on the tolerability of this drug and its long-term safety.

\section{References}

[1] Levy M, Feingold J. Estimating prevalence in single-gene kidney diseases progressing to renal failure. Kidney Int. 2000; 58 (3): 925.

[2] Carmen Garcia Iglesias, M. D., Vicente E. Torres, M. D., Kenneth P. Offord, M. S., Keith E. Holley, M. D., C. Mary Beard, R. N., M. P. H., and Leonard T. Kurland, M. D., Dr. P. H. Epidemiology of Adult Polycystic Kidney Disease, Olmsted County, Minnesota: 1935-1980. Am J Kidney Dis 1983 May; 2 (6) 630-9.

[3] Guías clínicas españolas: Poliquistosis renal autosómica dominante de la Sociedad Española de Nefrología. Rev 2015. Grupo de trabajo de enfermedades renales hereditarias. 
[4] Robert W. Schrier, M. D., Kaleab Z. Abebe, Ph. D., Ronald D. Perrone, M. D., Vicente E. Torres, M. D., Ph. D., William E. Braun, M. D., Theodore I. Steinman, M. D., Franz T. Winklhofer, M. D., Godela Brosnahan, M. D., Peter G. Czarnecki, M. D., Marie C. Hogan, M. D., Ph. D., Dana C. Miskulin, M. D., Frederic F. Rahbari-Oskoui, M. D., Jared J. Grantham, M. D., Peter C. Harris, Ph. D., Michael F. Flessner, M. D., Ph. D., Kyongtae T. Bae, M. D., Charity G. Moore, Ph. D., M. S. P. H., and Arlene B. Chapman, M. D. Blood Pressure in Early Autosomal Dominant Polycystic Kidney Disease. March 5, 2015 N Engl J Med 2015; 372: 975-977.

[5] Torres VE, Harris PC, Pirson Y Autosomal dominant polycystic kidney disease. Lancet. 2007; 369 (9569): 1287.

[6] Emilie Cornec-Le Gall, Vicente E. Torres and Peter C. Harris Genetic Complexity of Autosomal Dominant Polycystic Kidney and Liver Diseases. J Am Soc Nephrol 2017.

[7] Cornec-Le Gall E, Audrézet MP, Chen JM, Hourmant M, Morin MP, Perrichot R, Charasse C, Whebe B, Renaudineau E, Jousset P, Guillodo MP, Grall-Jezequel A, Saliou P, Férec C, Le Meur Y. Type of PKD1 mutation influences renal outcome in ADPKD. J Am Soc Nephrol. 2013 May; 24 (6): 1006-13.

[8] Mochizuki T, Wu G, Hayashi T, Xenophontos SL, Veldhuisen B, Saris JJ, Reynolds DM, Cai Y, Gabow PA, Pierides A, Kimberling WJ, Breuning MH, Deltas CC, Peters DJ, Somlo S. PKD2, a gene for polycystic kidney disease that encodes an integral membrane protein. Science. 1996 May 31; 272 (5266): 1339-42.

[9] The polycystic kidney disease 1 gene encodes a $14 \mathrm{~kb}$ transcript and lies within a duplicated region on chromosome 16. The European Polycystic Kidney Disease Consortium. Cell. 1994 Aug 26; 78 (4): 725.

[10] Porath B, Gainullin VG, Cornec-Le Gall E, Dillinger EK, Heyer CM, Hopp K, Edwards ME, Madsen CD, Mauritz SR, Banks CJ, Baheti S, Reddy B, Herrero JI, Bañales JM, Hogan MC, Tasic V, Watnick TJ, Chapman AB, Vigneau C, Lavainne F, Audrézet MP, Ferec C, Le Meur Y, Torres VE, Genkyst Study Group, HALT Progression of Polycystic Kidney Disease Group, Consortium for Radiologic Imaging Studies of Polycystic Kidney Disease, Harris PC. Mutations in GANAB, Encoding the Glucosidase II $\alpha$ Subunit, Cause AutosomalDominant Polycystic Kidney and Liver Disease. Am J Hum Genet. 2016 Jun; 98 (6): 1193-207.

[11] Grantham JJ, Mulamalla S, Swenson-Fields KI. Why kidneys fail in autosomal dominant polycystic kidney disease. Nat Rev Nephrol 2011; 7: 556-566.

[12] Carney EF. Polycystic kidney disease: Cyst growth and cilia in ADPKD. Nature Reviews Nephrology 2013. Oct; 9 (10): 555.

[13] Pei Y, Obaji J, Dupuis A, Paterson AD, Magistroni R, Dicks E, Parfrey P, Cramer B, Coto E, Torra R, San Millan JL, Gibson R, Breuning M, Peters D, Ravine D. Unified criteria for ultrasonographic diagnosis of ADPKD. J Am Soc Nephrol. 2009 Jan; 20 (1): 205-12.

[14] Ravine D, Gibson RN, Walker RG, Sheffield LJ, KincaidSmith P, Danks DM. Evaluation of ultrasonographic diagnostic criteria for autosomal dominant polycystic kidney disease 1. Lancet. 1994 Apr 2; 343 (8901): 824-7.

[15] Irazabal MV, Rangel LJ, Bergstralh EJ, Osborn SL, Harmon AJ, Sundsbak JL, Bae KT, Chapman AB, Grantham JJ, Mrug M, Hogan MC, El-Zoghby ZM, Harris PC, Erickson BJ, King
$\mathrm{BF}$, Torres VE; Imaging classification of autosomal dominant polycystic kidney disease: a simple model for selecting patients for clinical trials. J Am Soc Nephrol. 2015 Jan; 26 (1): $160-72$.

[16] R. Torra Balcells, E. Ars Criach. Diagnóstico molecular de la poliquistosis renal autosómica dominante. Revista Nefrologia 2011; 31 (1): 35-43.

[17] Klahr S, Breyer JA, Beck GJ, Dennis VW, Hartman JA, Roth D, Steinman TI, Wang SR, Yamamoto ME. Dietary protein restriction, blood pressure control, and the progression of polycystic kidney disease. Modification of Diet in Renal Disease Study Group. J Am Soc Nephrol. 1995 Jun; 5 (12): 2037-47.

[18] Gansevoort RT, Arici M, Benzing T, Birn H, Capasso G, Covic A, Devuyst O, Drechsler C, Eckardt KU, Emma F, Knebelmann B, Le Meur Y, Massy ZA, Ong AC, Ortiz A, Schaefer F, Torra R, Vanholder R, Więcek A, Zoccali C, Van Biesen W. Recommendations for the use of tolvaptan in autosomal dominant polycystic kidney disease: a position statement on behalf of the ERA-EDTA Working Groups on Inherited Kidney Disorders and European Renal Best Practice. Nephrol Dial Transplant. 2016 Mar; 31 (3): 337-48.

[19] Torres VE, Gansevoort RT, Czerwiec FS. Tolvaptan in autosomal dominant polycystic kidney disease. N Engl J Med. 2013 Mar 28; 368 (13): 1259.

[20] Vicente E. Torres, M. D., Ph. D., Arlene B. Chapman, M. D., Olivier Devuyst, M. D., Ph. D., Ron T. Gansevoort, M. D., Ph. D., Jared J. Grantham, M. D., Eiji Higashihara, M. D., Ph. D., Ronald D. Perrone, M. D., Holly B. Krasa, M. S., John Ouyang, Ph. D., and Frank S. Czerwiec, M. D., Ph. D. Tolvaptan in Patients with Autosomal Dominant Polycystic Kidney Disease. N Engl J Med 2012; 367; 2.

[21] Torres VE, Chapman AB, Devuyst O, Gansevoort RT, Perrone RD, Dandurand A, Ouyang J, Czerwiec FS, Blais JD; TEMPO 4:4 Trial Investigators. Multicenter, open-label, extension trial to evaluate the long-term efficacy and safety of early versus delayed treatment with tolvaptan in autosomal dominant polycystic kidney disease: the TEMPO 4:4 Trial. Nephrol Dial Transplant. 2018 Mar 1; 33 (3): 477-489.

[22] Jared J. Grantham, M. D., Vicente E. Torres, M. D., Arlene B. Chapman, M. D., Lisa M. Guay-Woodford, M. D., Kyongtae T. Bae, M. D., Ph. D., Bernard F. King, Jr., M. D., Louis H. Wetzel, M. D., Deborah A. Baumgarten, M. D., Phillip J. Kenney, M. D., Peter C. Harris, Ph. D., Saulo Klahr, M. D., William M. Bennett, M. D., et al., for the CRISP Investigators. Volume Progression in Polycystic Kidney Disease. N Engl J Med 2006; 354: 2122-2130.

[23] Alam A, Dahl NK, Lipschutz JH, Rossetti S, Smith P, Sapir D, Weinstein J, McFarlane P, Bichet DG. Total Kidney Volume in Autosomal Dominant Polycystic Kidney Disease: A Biomarker of Disease Progression and Therapeutic Efficacy. Am J Kidney Dis. 2015 Oct; 66 (4): 564-76.

[24] Cornec-Le Gall E, Audrézet MP, Rousseau A, Hourmant M, Renaudineau E, Charasse C, Morin MP, Moal MC, Dantal J, Wehbe B, Perrichot R, Frouget T, Vigneau C, Potier J, Jousset P, Guillodo MP, Siohan P, Terki N, Sawadogo T, Legrand D, Menoyo-Calonge V, Benarbia S, Besnier D, Longuet H, Férec C, Le Meur Y. The PROPKD Score: A New Algorithm to Predict Renal Survival in Autosomal Dominant Polycystic Kidney Disease. J Am Soc Nephrol. 2016 Mar; 27 (3): 942-51. 
[25] Devuyst O, Chapman AB, Gansevoort RT, Higashihara E, Perrone RD, Torres VE, Blais JD, Zhou W, Ouyang J, Czerwiec FS. Urine Osmolality, Response to Tolvaptan, and Outcome in Autosomal Dominant Polycystic Kidney Disease: Results from the TEMPO 3:4 Trial. J Am Soc Nephrol. 2017 May; 28 (5): 1592-1602. 